\title{
Cognitive reserve modulates functional brain responses during memory tasks: a PET study in healthy young and elderly subjects
}

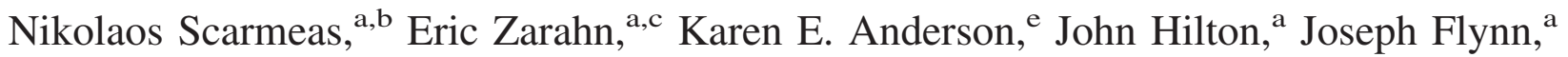 \\ Ronald L. Van Heertum, ${ }^{\mathrm{d}}$ Harold A. Sackeim, ${ }^{\mathrm{c}, \mathrm{d}}$ and Yaakov Stern ${ }^{\mathrm{a}, \mathrm{b}, \mathrm{c}, *}$ \\ ${ }^{\text {a }}$ Cognitive Neuroscience Division of the Taub Institute for Research in Alzheimer's Disease and the Aging Brain, New York, NY 10032, USA \\ ${ }^{\mathrm{b}}$ Department of Neurology, College of Physicians and Surgeons of Columbia University, New York, NY 10032, USA \\ ${ }^{\mathrm{c}}$ Department of Psychiatry, College of Physicians and Surgeons of Columbia University, New York, NY 10032, USA \\ d Department of Radiology, College of Physicians and Surgeons of Columbia University, New York, NY 10032, USA \\ ${ }^{\mathrm{e}}$ Department of Psychiatry, University of Maryland, Baltimore, MD 21201, USA
}

Received 15 September 2002; accepted 15 January 2003

\begin{abstract}
Cognitive reserve (CR) is the ability of an individual to cope with advancing brain pathology so that he remains free of symptomatology. Epidemiological evidence and in vivo neurometabolic data suggest that CR may be mediated through education or IQ. The goal of this study was to investigate CR-mediated differential brain activation in 17 healthy young adults and 19 healthy elders. Using nonquantitative $\mathrm{H}_{2}{ }^{15} \mathrm{O}$ PET scanning, we assessed relative regional cerebral blood flow while subjects performed a serial recognition memory task under two conditions: nonmemory control (NMC), in which one shape was presented in each study trial; and titrated demand (TD), in which study list length was adjusted so that each subject recognized shapes at approximately $75 \%$ accuracy. A factor score that summarized years of education and scores on two IQ indices was used as an index of CR. Voxel-wise, multiple regression analyses were performed with TD minus NMC difference PET counts as the dependent variable and the CR variable as the independent variable of interest. We identified brain regions where regression slopes were different from zero in each separate group, and also those where regression slopes differed between the two age groups. The slopes were significantly more positive in the young in the right inferior temporal gyrus, right postcentral gyrus, and cingulate, while the elderly had a significantly more positive slope in left cuneus. Brain regions where systematic relationships between $\mathrm{CR}$ and brain activation differ as a function of aging are loci where compensation for aging has occurred. They may mediate differential ability to cope with brain changes in aging.
\end{abstract}

(c) 2003 Elsevier Science (USA). All rights reserved.

The theory of cognitive reserve (CR) was initially introduced as an attempt to explain less than perfect coupling between the degree of brain pathology and its clinical expression. For example, about $25 \%$ of subjects who during autopsy fulfill pathologic criteria for Alzheimer's disease (AD) are clinically intact during life (Ince, 2001; Katzman et al., 1989). CR can be defined as the ability of an individual to cope with advancing brain pathology in order to minimize symptomatology. It may be mediated through a set of skills or repertoires or inherent abilities (putative "CR

\footnotetext{
* Corresponding author. Gertrude H. Sergievsky Center, 630 West $168^{\text {th }}$ Street, New York, NY 10032.

E-mail address: ys11@ columbia.edu (Y. Stern).
}

variables") such as education (Stern et al., 1992, 1994), or IQ (Alexander et al., 1997; Snowdon et al., 2000) or even lifestyle either in the form of occupational status (Stern et al., 1994, 1995) or extracurricular activities (Scarmeas et al., 2001). The neurophysiologic substrate of CR can be conceived in two forms (Stern, 2002): (1) passive (or "hardware"): higher number of healthy synapses or neurons resulting in an increased number of remaining available ones when a certain percentage of them is affected by a pathologic process; and (2) active (or "software"): more efficient synaptic processing in normal brain networks or use of alternative brain networks in the face of progressing pathology (even though the number of neurons or synapses might be the same). 
Both regional cerebral blood flow $(\mathrm{rCBF})$ and regional cerebral glucose metabolism (rCMRglc) are reliable indices of neuronal/synaptic function and therefore they may provide a valuable in vivo index of the effects of the neuropathological process on brain function in patients with $\mathrm{AD}$ (DeCarli et al., 1992; Friedland et al., 1985; Hoffman et al., 2000; McGeer et al., 1986a, 1986b, 1990a, 1990b; Mielke et al., 1996) Supporting the concept of CR, PET studies in AD subjects matched for clinical severity have reported negative correlations between rCMRglc or rCBF performed in subjects in the resting state and education, IQ, occupation, and leisure activities (Alexander et al., 1997; Scarmeas et al., 2002; Stern et al., 1992, ). Therefore, for a given degree of clinical severity, AD subjects with a higher level of CR will tend to harbor more severe neuropathology than $\mathrm{AD}$ subjects with a lower level of CR. In other words, patients with a higher level of $\mathrm{CR}$ who are at a more advanced neuropathological stage of $\mathrm{AD}$ can have similar clinical manifestations to patients with a low level of $\mathrm{CR}$ who are at a less advanced AD neuropathological stage.

These in vivo metabolic findings concern the relationship between resting $\mathrm{rCBF}$ or rCMRglc and $\mathrm{CR}$ variables. The concept of CR should also be relevant when considering changes in blood flow associated with cognition. Furthermore, this concept might possibly be relevant to populations other than AD. For example, it can be hypothesized that healthy young subjects with high values of CR variables may have an enhanced hardware (Katzman, 1993; Kempermann et al., 1997a, 1997b; van Praag et al., 1999) or software relative to otherwise healthy young subjects with a lower level of the CR variables. Also, CR may convey differential ability to cope with declining neurophysiologic potential in otherwise healthy elderly (Cabeza, 2001). Such changes in hardware or software might predict relationships between CR variables and task-related neurophysiological activity in each population, and so be amenable to testing with functional neuroimaging.

Previous studies have noted that compared to younger subjects, the elderly may have reduced brain activation in regions found activated in the younger (Cabeza et al., 2000; Reuter-Lorenz, 2002; Grady et al., 1994, 1995, 1996; Backman et al., 1999; Stern et al., 2000), which has been interpreted as reflecting less efficient cognitive processing or processing deficiency either due to irreversible absence of cognitive resources or to inability to engage-recruit them despite their presence (Craik and Byrd, 1982). Nevertheless, at the same time elderly may show significant activations of areas not engaged by the younger subjects (Anderson et al., 2000; Grady et al., 1994; Reuter-Lorenz, 2002; ReuterLorenz et al., 2000; Logan et al., 2002; Madden et al., 1999; McIntosh et al., 1999). The latter has been perceived as an attempt to deal with increased (for the elderly) task complexity and therefore counteract age-related (or other) deficits (Cabeza, 2001; Cabeza et al., 2000, 2002). In other words, compensatory reallocation of brain function has been considered an effort to ameliorate the effects of re- duced function in the networks that normally operate during the task. Nevertheless, the interpretation of either increased or decreased activation has been very controversial. There have been studies where decreased activation may reflect more efficient processing, while increased ones may be associated with less effective cognitive strategies (Grady et al., 1996; Rypma and D'Esposito, 2001; Cabeza et al., 2000; Madden et al., 1999). Therefore, CR may act differentially (i.e., in a different manner on distinct brain regions) in young and older people.

We sought to investigate the existence and nature of systematic relationships between CR variables and neurophysiological function in samples of healthy young and elderly subjects during performance of a nonverbal (abstract shape) episodic memory task. Subject performance on the memory task was titrated to yield accuracy close to $75 \%$ for each subject in both groups. This procedure was used in an attempt to equate subjective task difficulty across subjects (and implicitly across age groups); objective task characteristics were thus not identical either within or between groups. Proportionally scaled $\mathrm{H}_{2}{ }^{15} \mathrm{O}$ positron emission tomography count data were used as the measure of neurophysiological activity.

\section{Materials and methods}

\section{Subjects}

Potential subjects were carefully screened with medical, neurological, psychiatric, and neuropsychological evaluations to exclude those with dementia, questionable dementia, cognitive impairment, or other neurological or psychiatric disorders and severe medical illnesses. They all received a brain MRI which was evaluated as normal by a neuroradiologist and they were all screened for medications with potential effects on brain function / metabolism / blood flow (like central nervous system-acting medications prescribed for neurologic or psychiatric diseases). In particular, older subjects were carefully evaluated to ensure the absence of dementia. All subjects were right-handed and able to see stimuli clearly without optometric correction. Seventeen healthy elders (8 male and 9 female) and 19 young volunteers ( 7 male and 13 female) met criteria for entry into the study. Informed consent was obtained after the nature and risks of the study were explained.

\section{Neuropsychological evaluation $C R$ variables and cognitive tasks}

In addition to neurological and psychiatric evaluation, patients also received the modified Mini Mental Status (Mayeux et al., 1981; Stern et al., 1987). The Mini-Mental State Examination described by Folstein et al. (1975) is a useful screening instrument, but does not sufficiently measure some aspects of language, attention, and construction. 
The mMMS was developed in order to broaden its scope: it includes the standard Folstein Mini-Mental plus additional measures of memory, attention, calculation, naming, repetition, and visual spatial skills (maximum score 57, corresponding to a Mini-Mental State Examination of 30). It is sensitive to a variety of impairments in $\mathrm{AD}$, and has established validity and reliability (Mayeux et al., 1981; Stern et al., 1987). The WAIS-R Digit Symbol (Wechsler, 1981) and the Selective Reminding Test (Buschke and Fuld, 1974) were also administered in order to assess psychomotor speed and memory.

The neuropsychological tests used to measure CR were the New Adult Reading Test (NARTIQ)-North American Version (Grober and Sliwinski, 1991; Nelson, 1982; Nelson and O'Connell, 1978) and the WAIS-R Vocabulary subtest (VOC) (Wechsler, 1981). The two latter tests are considered to be good estimates of premorbid verbal IQ. An operational measure of $\mathrm{CR}$ (CR variable; $\mathrm{CRV}$ ) was defined as the principal component of $z$-scored NARTIQ, VOC, and years of education (EDUC) with the largest eigenvalue (analysis done on the sample of subjects used in this study). CRV was to be used in the assessment of relationships between the neuroimaging data and $\mathrm{CR}$. The rationale for the choice of these three variables as being representative of $\mathrm{CR}$ is provided by the literature on CR (Alexander et al., 1997; Snowdon et al., 2000; Stern et al., 1992, 1994). From this premise, NARTIQ, VOC, and EDUC should be pair-wise, positively correlated; the data from our sample (collapsed across age group) support this (NARTIQ-VOC $r=0.71$, $P<0.01$, NART-EDUC $r=0.73, P<0.01$, VOC-EDUC $r=0.47, P<0.01)$. CRV explained $73 \%$ of the total variance of these (z-scored) measures.

The nonverbal episodic memory task used in the neuroimaging component of this study comprised three conditions (though only two of them were used in the current analysis; see below). In each condition, a trial comprised an encoding phase followed by a recognition phase. During each recognition phase, subjects made decisions about whether the current shape had been presented in the encoding phase of that trial. Recognition probes were distinguished from study items by a rectangular frame.

The three conditions were:

(1) a low-demand condition, in which a single shape presented during the encoding phase was followed by one shape during the recognition phase (which was either the same as the encoding phase shape or a nonfamiliar foil). This condition was relevant for other experimental purposes and was not used in the current analysis.

(2) a nonmemory control (NMC) condition that was identical to low demand, except that the same shape was presented during the encoding phase of every trial. Thus the NMC had very low encoding and recognition demands. Either the same encoding phase shape or a nonfamiliar foil was presented during the recognition phase.

(3) a titrated demand (TD) condition that involved serial presentation of a sequence of shapes during the encoding phase, the length of which was determined in a training session on the day preceding the PET scan. During this training session, the subjects were at first familiarized with all three conditions for approximately 10 min total. This initial exposure to the task was followed by the determination of the shape list size for the TD condition. This titration procedure involved two 15-minute titration sessions during which shape list size was adjusted in a staircase manner such that recognition accuracy of about $75 \%$ for each individual subject was attained. This shape list size value was then used in the TD condition on the day of the scan. The recognition phase of the TD condition involved presentation of shapes studied during the preceding study phase intermixed with nonfamiliar foils. The total number of shapes presented in each trial during the recognition phase was equal to each subject's shape list size during testing.

We elected to fix the order of the conditions in this study (as opposed to randomization or counterbalancing). The rationale for this fixing of condition order is that, in addition to the young and elderly subjects whose data are to be presented here, AD patients were subjected to this experimental design. Three other scans, using a verbal recognition task, were also collected. Therefore, overall $3 \times 2=6$ activation scans were obtained. The fixed order was intended to minimize subject confusion (particularly in the Alzheimer's patients) that conceivably would have been caused by switching order between low-demand conditions, NMC condition (both quite easy), and TD condition and between verbal and nonverbal tasks (i.e., using a task order other than the natural progression of increasing task difficulty). The consequence of using a fixed task order is the possibility of confounding between condition and position in the task sequence.

During study phases in the scanner, young subjects were exposed to each stimulus for $4 \mathrm{~s}$ and elderly for $5 \mathrm{~s}$. This was true for all conditions. This was a decision made during the development of task design as an adjunctive attempt to equate for task difficulty and subject-related effort. Although it may have introduced an experimental variable that may affect differential neuronal recruitment, its significance for results interpretation depends on what is the critical variable to equate for (difficulty vs task parameters). We take up this issue in the Discussion. A single run was performed for each condition. A 500-ms delay occurred at the transition to test trials, after which the recognition probes were displayed. During the recognition phase in the scanner subjects were instructed to make a "New" or "Old" response for each probe item by pressing one of two mi- 

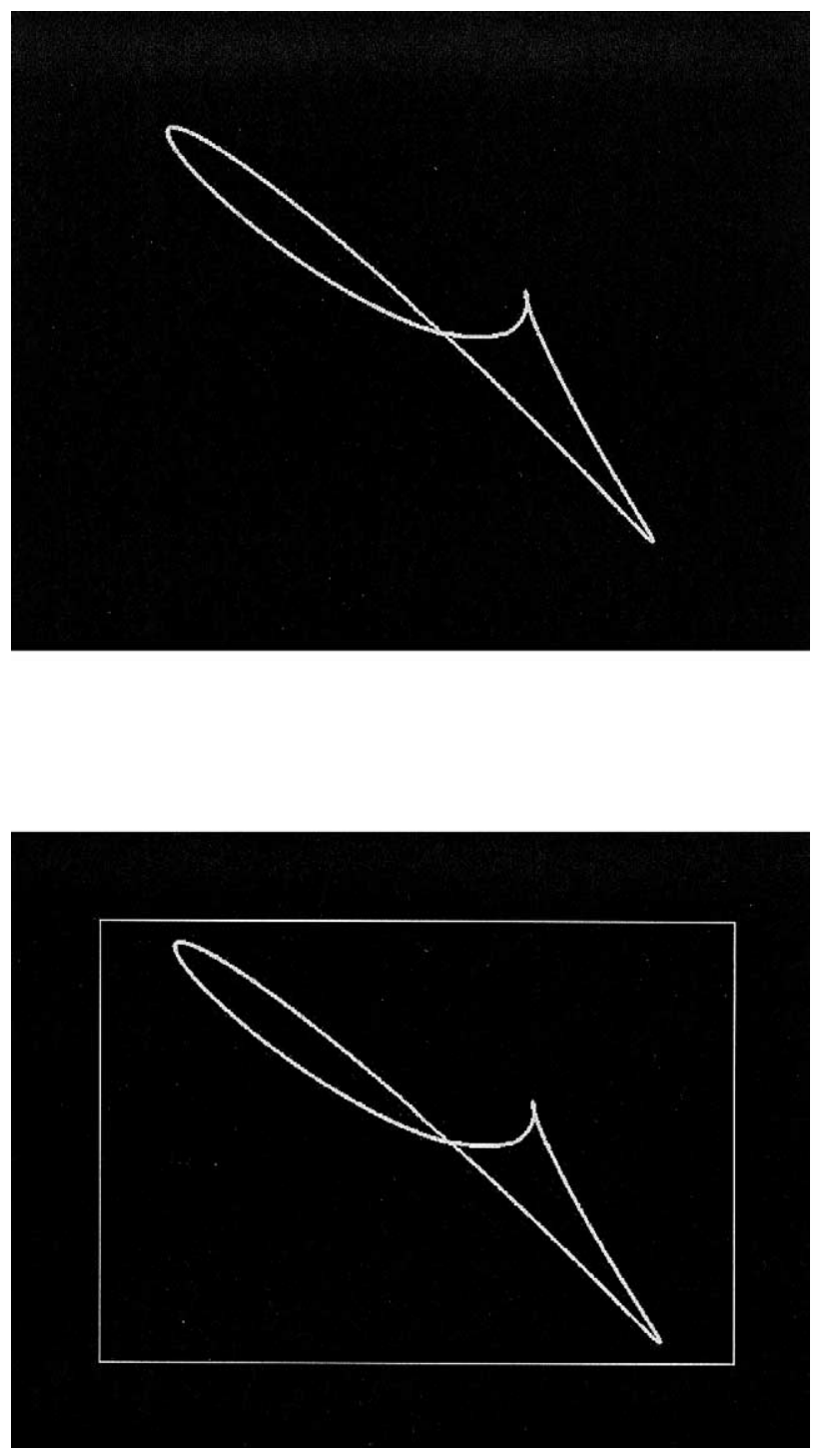

Fig. 1. Samples of the shapes used in the nonverbal recognition task. The surrounding rectangle denotes probe items.

croswitches (left for "New", right thumb for "Old"). A 6-s response time limit was imposed, with a premature response cutoff of $200 \mathrm{~ms}$. Accuracy was emphasized over speed. A new test probe was displayed immediately following the button press. "New" and "Old" test probes each occurred with a frequency of 50\%. Test probes were pseudorandomized so that no more than four consecutive trials required the same response.

Each shape was used only once for each subject. The set of shapes were designed to have similar characteristics that varied randomly within given sets of parameters. Looped shapes were used since their level of complexity made verbal encoding difficult (Fig. 1). The stimuli were prescreened to ensure that they could not be easily given a name, and a separate screening study established that elderly subjects could recognize each shape.

\section{PET scan acquisition}

Each condition was initiated $50 \mathrm{~s}$ prior to the start of the scan and continued throughout it. Subjects viewed the shape stimuli on an overhead monochrome monitor while lying in a supine position. Scans were separated by $10 \mathrm{~min}$ and were obtained in the following order: scan at rest (eyes closed), NMC, low demand, and TD.

For each scan, a bolus of $30 \mathrm{mCi} \mathrm{H}_{2}{ }^{15} \mathrm{O}$ was injected intravenously. Scan acquisition was triggered by the detection of a threshold level of true counts from the camera. Employing a Siemens EXACT 47 PET camera (Knoxville, TN), two 30-s scan frames were acquired in 2D mode. These two frames were subsequently averaged. After measured attenuation correction (15-min transmission scan) and reconstruction by filtered back-projection, image resolution was $4.6 \mathrm{~mm}$ full-width at half-maximum (FWHM). Arterial blood sampling was not conducted; thus only nonquantitative count images (and not absolute rCBF measures) could be obtained. The use of this nonquantitative measure of $\mathrm{rCBF}$ is a limitation of our study because it necessitates global normalization (proportional scaling) that restricts inferences to task-related changes relative to the whole brain average. For economy of notation, proportionally scaled PET counts are referred to as "rCBF" values, with the understanding that they are not in physiologic units.

\section{PET data processing}

The SPM99 program (Wellcome Department of Neurology) was used to implement the following standard steps for the PET images of each subject:

(1) a mean image was generated

(2) all images were then realigned to the mean image

(3) this mean image was used to determine a spatial transformation to the PET Montreal Neurologic Institute brain space template included with SPM99

(4) this spatial transformation was then applied to the individual images

(5) normalized images were smoothed with an isotropic, Gaussian kernel (FWHM $=12 \mathrm{~mm}$ )

(6) these images were proportionally scaled by their global mean

(7) group data were modeled voxel-wise with a separate GLM for each pair of conditions (see below for details of GLM design)

(8) voxel-wise $t$ statistics corresponding to contrasts of interest were computed

(9) Montreal Neurological Institute coordinates of local maxima of thresholded $\left(\alpha_{\text {corrected }}=0.05\right)$ SPM (1994) maps were converted to standard Talairach brain atlas (Talairach and Tarnoux, 1988) coordinates (via program authored by Matthew Brett; http:// www.mrccbu.cam.ac.uk/Imaging/mnispace.html) 
Table 1

Demographic characteristics, neuropsychological profile, and behavioral-cognitive performance during the experimental paradigm in the two age groups

\begin{tabular}{|c|c|c|c|c|c|}
\hline & \multicolumn{2}{|l|}{ Young } & \multicolumn{2}{|l|}{ Elderly } & \multirow[t]{2}{*}{$P$ Value } \\
\hline & Mean (range) & $\begin{array}{l}\text { Standard } \\
\text { deviation }\end{array}$ & Mean (range) & $\begin{array}{l}\text { Standard } \\
\text { deviation }\end{array}$ & \\
\hline Age & $23(19-28)$ & 24 & $71(59-81)$ & 7 & $<0.001$ \\
\hline $\begin{array}{l}\text { Modified Mini Mental } \\
\text { Status examination }\end{array}$ & $55.7 / 57(53-57)$ & 1.1 & $54.2 / 57(48-57)$ & 2.5 & $<0.035$ \\
\hline SRT Total recall & $58.7(43-69)$ & 7.1 & $46.9(32-63)$ & 7.7 & $<0.001$ \\
\hline SRT Delayed recall & $10.3(7-12)$ & 1.5 & $6.9(0-11)$ & 2.9 & $<0.001$ \\
\hline Digit symbol WAIS-R & $12.1(5-17)$ & 3.1 & $12.7(9-16)$ & 2.4 & 0.521 \\
\hline Education & $16.7(13-20)$ & 1.9 & $15(7-20)$ & 4.1 & 0.119 \\
\hline NARTIQ & $121.1(115-127)$ & 3.4 & $121.1(101-129)$ & 6.9 & 0.995 \\
\hline Vocabulary WAIS-R & $13.5(9-15)$ & 1.5 & $13.8(9-18)$ & 2.5 & 0.671 \\
\hline Accuracy (\% correct) & $0.78(0.59-0.89)$ & 0.08 & $0.72(0.61-0.84)$ & 0.07 & 0.051 \\
\hline TD list length & $14.1(5-35)$ & 6.2 & $7.5(3-19)$ & 4.8 & 0.001 \\
\hline
\end{tabular}

Note. Student's $t$ test was used for $P$ value calculations.

(10) an automated procedure was used to assign an anatomic label to these coordinates by searching for the label associated with the nearest gray matter coordinate (Lancaster et al., 2000).

\section{General linear model design for PET data}

Voxel-wise, multiple regression analyses (Friston et al., 1995) were performed with proportionally scaled PET counts as the dependent variable. Due to the paired nature of the data, the dependent variable for the regression was equivalent to the difference between TD and NMC test condition PET counts. This difference was meant to represent functional activation related to titrated memory performance, while subtracting out activity related to basic sensory and motor processing.

The regressions modeled the effects of condition $\times$ $\mathrm{CRV}$, and condition $\times$ group $\times \mathrm{CRV}$ (as well as all main effects and lower order interactions which are not presented in this paper). The condition $\times \mathrm{CRV}$ interaction represents the relationship between $\mathrm{CRV}$ and task-related activation within each group, and assessing it is critical to testing the hypothesis that CR plays a role in the neurophysiology of memory in young and healthy elderly populations. The three-way interaction speaks to the hypothesis that this role differs between these populations.

Even though the purpose of the titration procedure was to constrain accuracy at $75 \%$ in the TD condition, there were residual deviations from this target value. Moreover, there was a modest positive correlation between CRV and subject accuracy in the TD condition $(r=0.42, P<0.05)$. Therefore, each subjects's accuracy (expressed as percentage correct) in the TD condition was included as a nuisance predictor variable in the regressions to obviate confounding of CRV and TD accuracy.

Other nuisance variables were also included which accounted for possible relationships between TD minus NMC activation and (1) the two other variables yielded by the principal components analysis of NARTIQ, VOC, and EDUC (described above) as well as with (2) TD list size. These predictor variables were orthogonalized with respect to all the others (Andrade et al., 1999; Zarahn, 2002), as the purpose of their inclusion was not to avoid confounding but to explain other possible variance components in the data in order to increase sensitivity (Friston et al., 1995).

\section{Results}

\section{Demographics/behavioral}

Subjects' demographic characteristics, neuropsychologic profile, and behavioral-cognitive performance during the experimental paradigm are presented in Table 1. As expected, young subject memory performance was superior (SRT total recall and delayed recall). Overall modified Mini Mental Status Examination score was better for the young while psychomotor speed (Digit Symbol), although better for the young, was not statistically different between groups. Neither EDUC, NARTIQ, VOC, nor CRV (which is a summary of the former three measures) differed significantly between the two groups.

The young were able to achieve a larger TD list size compared to the elderly (Table 1). The titration procedure did not work perfectly, however, as there was still a fair degree of variability in accuracy during the TD condition within the young and elderly samples. First order effects in the neuroimaging data of this residual variability in accuracy were accounted for by the inclusion of subject accuracy as a predictor.

\section{PET data}

Brain areas where CRV was significantly related to TD minus NMC PET counts are presented in Table 2 and Fig. 2 and 3 . In the young, positive correlations in the right 
Table 2

Areas where significant correlations between brain activation differences (TD-NMC) and CRV were detected $(P<0.05$ Bonferroni corrected) within each age group

\begin{tabular}{|c|c|c|c|c|c|c|}
\hline \multirow[t]{2}{*}{ Age group } & \multirow{2}{*}{$\begin{array}{l}\text { Direction of } \\
\text { correlation }\end{array}$} & \multicolumn{3}{|c|}{ Talairach coordinates } & \multirow{2}{*}{$\begin{array}{l}T \text { Values } \\
(d f=24)\end{array}$} & \multirow[t]{2}{*}{ Location (Brodmann's Area) } \\
\hline & & $x$ & $y$ & $z$ & & \\
\hline \multirow[t]{3}{*}{ Young } & Positive & 22 & -26 & 69 & 5.8 & Right Postcentral Gyrus (3) \\
\hline & & 65 & -57 & -6 & 4.9 & Right Inferior Temporal Gyrus (37) \\
\hline & Negative & - & - & - & - & - \\
\hline \multirow[t]{10}{*}{ Old } & Positive & 4 & -88 & 30 & 4.9 & Right Cuneus (19) \\
\hline & & 0 & -44 & 11 & 4.7 & Posterior Cingulate (29) \\
\hline & & 30 & -78 & 33 & 4.3 & Right Cuneus (19) \\
\hline & Negative & 55 & -40 & 17 & 6.5 & Right Superior Temporal Gyrus (13) \\
\hline & & -36 & -6 & -1 & 6.0 & Left Claustrum-Insula \\
\hline & & 38 & 2 & -7 & 4.8 & Right Superior Temporal Gyrus (38) \\
\hline & & -48 & -39 & 35 & 4.8 & Left Inferior Parietal Lobule (40) \\
\hline & & 4 & -25 & 34 & 5.6 & Cingulate Gyrus (31) \\
\hline & & 48 & 23 & 3 & 4.3 & Inferior Frontal Gyrus (47) \\
\hline & & -22 & -7 & -16 & 4.2 & Left Parahippocampal Gyrus \\
\hline
\end{tabular}

postcentral and inferior temporal gyri were observed. No negative correlations were noted in the young subjects. In the elderly, positive correlations in the right cuneus and posterior cingulate were observed. Negative associations between CRV and activation were noted in the right superior temporal gyrus, left claustrum, left inferior parietal lobule, cigulate, right inferior frontal gyrus, and left parahippocampal gyrus.

Table 3 displays brain regions where significant slope differences between the age groups were detected. Graphic representations of the slope differences reported in Table 3 are presented in Figs. 4 to 7; the corresponding brain locations are shown in Figs. 8 and 9. Compared to the young, elderly subjects had significantly more negative slopes in the right inferior temporal and postcentral gyri (Figs. 4-6 and 8 ) and significantly more positive slope in left cuneus (Figs. 7 and 9). Thus, the results support both that CR modulates neurophysiological activity within healthy young and elderly populations and that this effect differs between the two groups.

\section{Discussion}

This study was designed to explore the neural implementation of cognitive reserve in normal aging. The support for the concept of $\mathrm{CR}$ in $\mathrm{AD}$ comes from both epidemiological and resting imaging studies. Epidemiological data suggest that high education, occupation (Stern et al., 1994), or more active engagement in intellectual, social, and physical activities (Scarmeas et al., 2001; Wilson et al., 2002) is associated with decreased risk for incident dementia. AD patients with high education, occupation, or an engaged lifestyle can maintain similar clinical deficits to Alzheimer's patients with low education, occupation, or a nonengaged lifestyle despite more severe brain pathology as assessed by PET (Scarmeas et al., 2002; Stern et al., 1992, 1995).

Similar epidemiological data suggest that CR may operate similarly in response to the cognitive changes that occur in normal aging. It has been reported that individuals with higher levels of intellectual ability, education, and socioeconomic status are more likely to develop an engaged

\section{Positive Correlations}
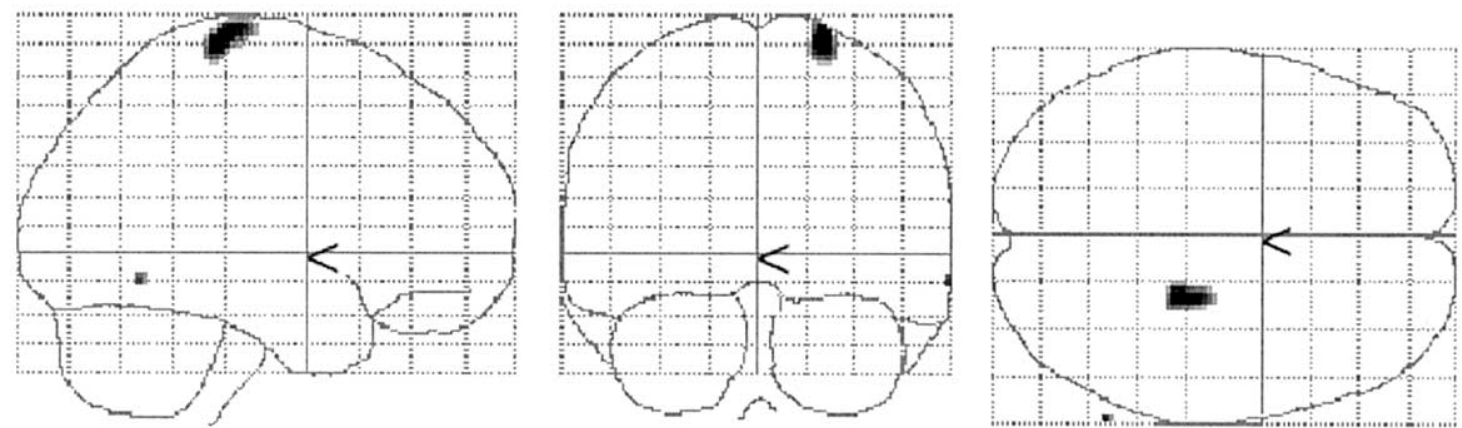

Fig. 2. Two-dimensional projections (glass brain) of statistical parametric map depicting areas where significant positive correlations between CRV and brain activation differences (TD-NMC) were noted in the young $(P<0.05$ Bonferroni corrected). No negative correlations were observed for the young. 


\section{Positive Correlations}
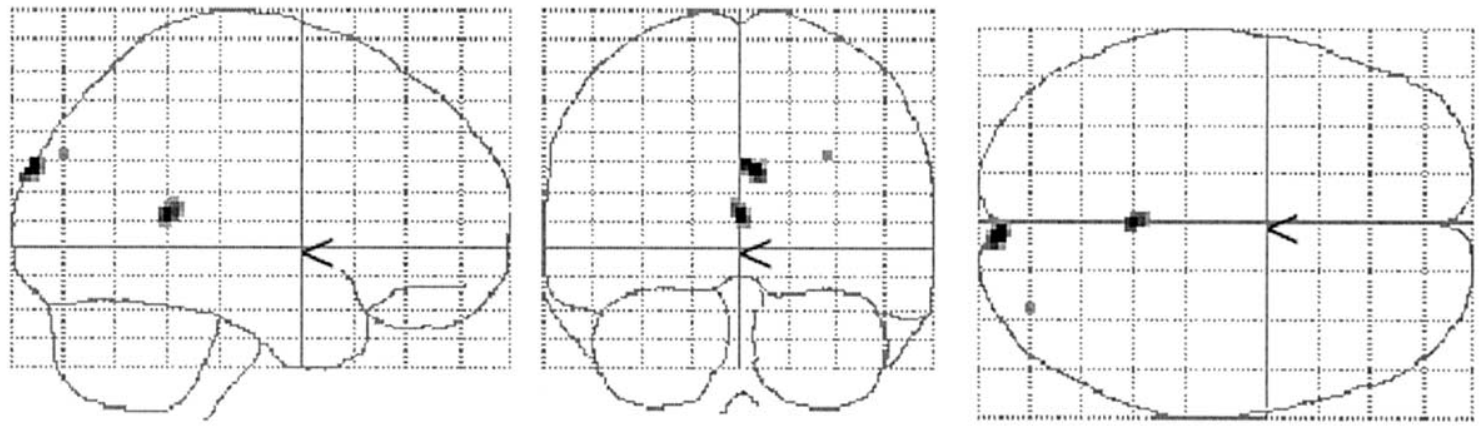

\section{Negative Correlations}
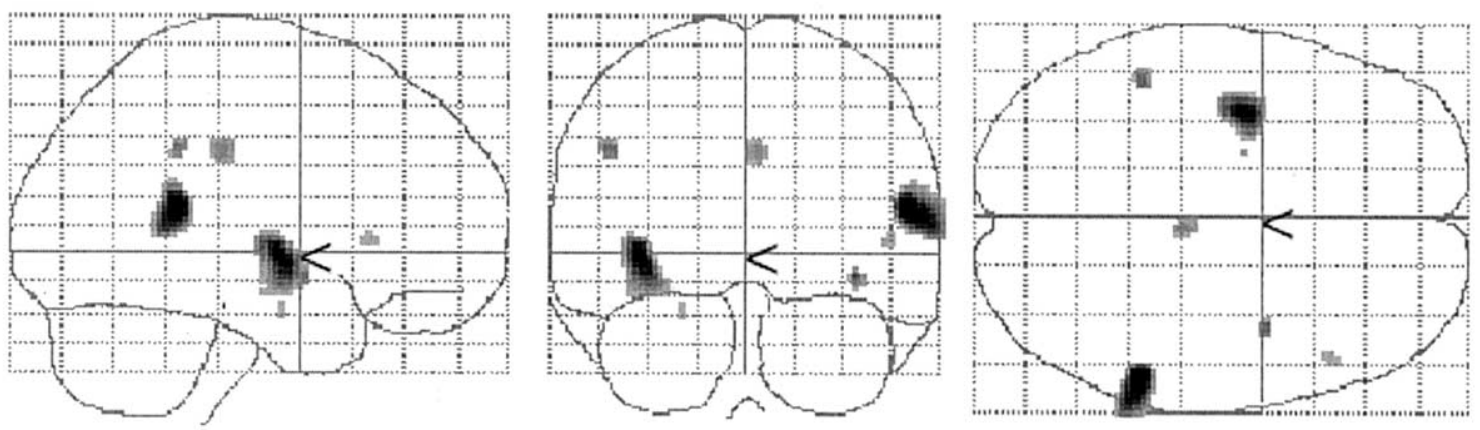

Fig. 3. Two-dimensional projections (glass brain) of statistical parametric map depicting areas where significant correlations between CRV and brain activation differences (TD-NMC) were noted in the elderly $(P<0.05$ Bonferroni corrected).

lifestyle, which in turn contributes to the maintenance of verbal intelligence in later life (Gold et al., 1995). In another study, among other factors, education was related to maintenance of intellectual performance in a sample of World War II veterans tested twice over a 40-year period (Arbuckle et al., 1992). Low education has been associated with poor health and function in older adults (Snowdon et al., 1989a, 1989b) as well as with a faster rate of cognitive decline (Butler et al., 1996; Nguyen et al., 2002).

Therefore, CR may be viewed as important for coping with the structural and functional changes that are noted in the brain's physiology with "normal aging." Both postmortem (Esiri, 1994; Kemper, 1994) and in vivo MRI studies (Raz et al., 1997) have documented loss in brain volume with aging (which might reflect neuronal death or atrophy). This is more prominent in prefrontal cortex but is present in other brain areas as well (Raz et al., 1997). White matter hyperintesities and atrophy are also noted (Raz et al., 1997). Lipofuscin accrues in neurons (Kemper, 1994), iron is deposited mostly in basal ganglia (Martin et al., 1998), and amyloid plaques and neurofibrillary tangles accumulate even in normal aging brains (Schochet, 1998). In addition, cholinergic, serotoninergic, and dopaminergic receptor losses occur (Strong, 1998). Finally, age-related cerebral blood flow and metabolism declines have been documented (de Leon et al., 1984, 1987; Ewing et al., 1989; Gur et al., 1987; Loessner et al., 1995; Madden and Hoffman, 1997; Meyer et al., 1993).

Table 3

Brain areas where regression slopes of CRV against brain activation differences (TD-NMC) were significantly different $(P<0.05$ Bonferroni corrected) among the two age groups

\begin{tabular}{lccccc}
\hline & \multicolumn{2}{c}{ Talairach coordinates } & & $T$ values $(d f=24)$ & Location (Brodmann's area) \\
\cline { 2 - 4 } & $x$ & $y$ & $z$ & & Right Inferior Temporal gyrus (37) \\
\hline Young slope more positive (than old slope) & 65 & -57 & -6 & 5.1 & Right Postcentral gyrus (3) \\
& 22 & -26 & 69 & 4.9 & Cingulate gyrus (31) \\
Old slope more positive (than young slope) & -26 & -26 & 34 & 4.4 & Left Cuneus (19) \\
\hline
\end{tabular}




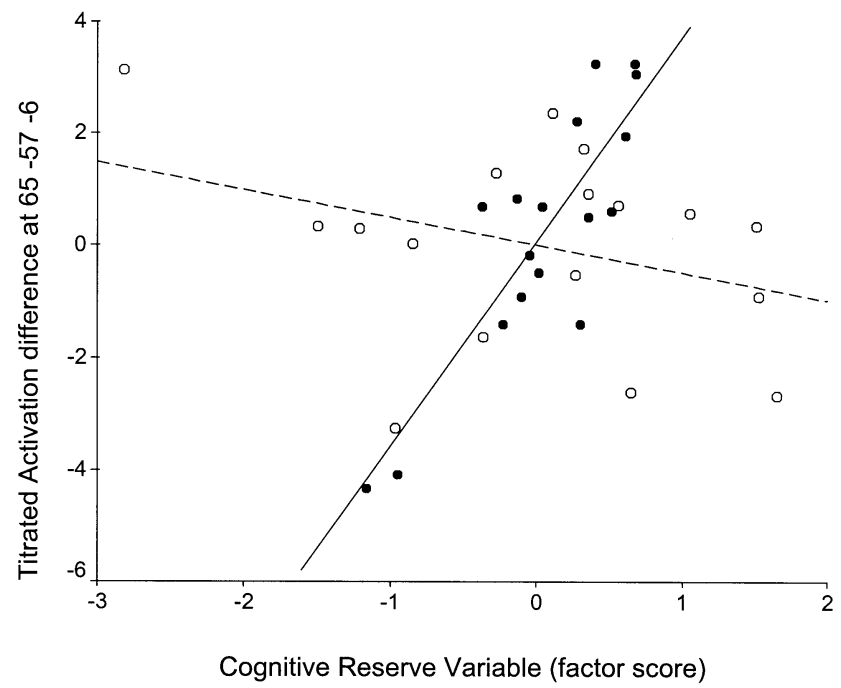

Fig. 4. Voxel-wise multiple regression of CRV ( $x$ axis) against TD-NMC ( $y$ axis) for the two age groups in voxel $x=65, y=-57, z=-6$ (right inferior temporal gyrus; Brodmann's area 37). Young in black circles-solid regression line, old in white circles-dashed regression line.

Activations in the elderly of areas not engaged by younger subjects (Anderson et al., 2000; Grady et al., 1994; Reuter-Lorenz, 2002; Reuter-Lorenz et al., 2000; Logan et al., 2002; Madden et al., 1999; McIntosh et al., 1999) has been interpreted as evidence of brain mechanisms that compensate for the effects of age-related neurophysiological damage cited above (Cabeza, 2001; Cabeza et al., 2000, 2002). Physiological details and formal neural network modeling concerning such compensatory mechanisms are yet to be developed.

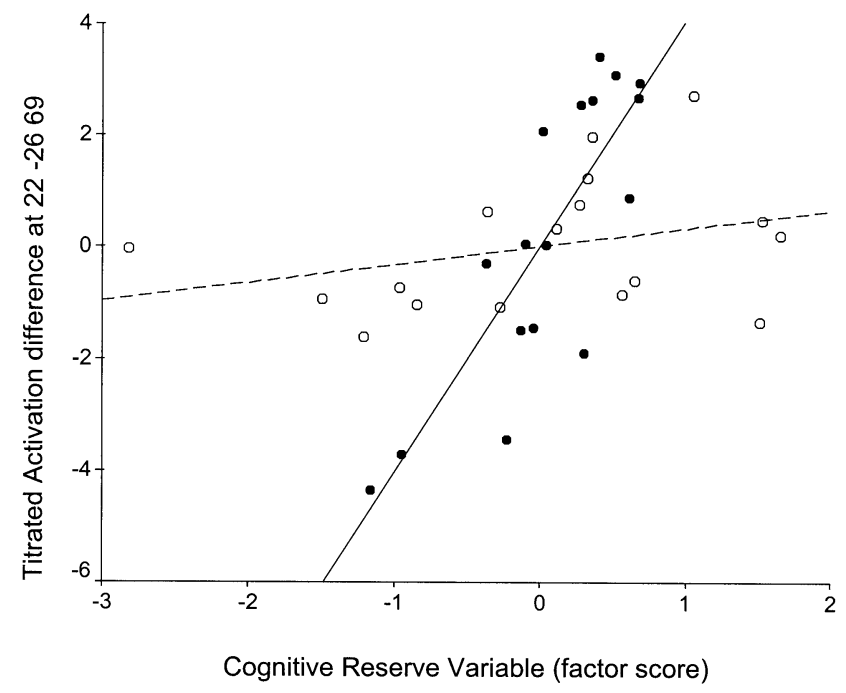

Fig. 5. Voxel-wise multiple regression of CRV ( $x$ axis) against TD-NMC ( $y$ axis) for the two age groups in voxel $x=22, y=-26, z=69$ (right postcentral gyrus; Brodmann's area 3). Young in black circles-solid regression line, old in white circles-dashed regression line.

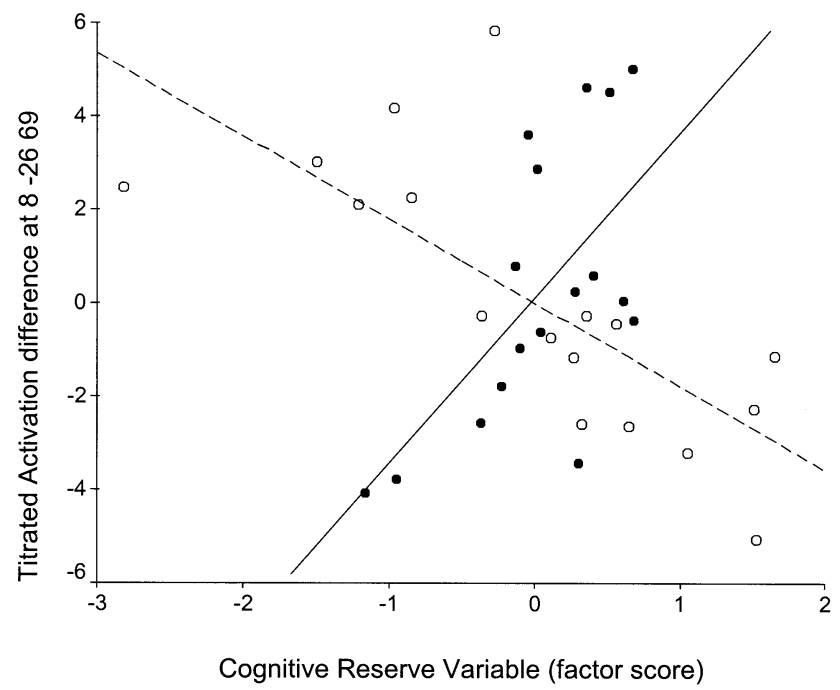

Fig. 6. Voxel-wise multiple regression of CRV ( $x$ axis) against TD-NMC ( $y$ axis) for the two age groups in voxel $x=8, y=-26, z=69$ (cingulate gyrus; Brodmann's area 31). Young in black circles-solid regression line, old in white circles-dashed regression line.

\section{Task difficulty}

Increased activation has to be considered under the factor of increased (for the elderly) task complexity. Several functional imaging studies suggest that a common response to increasing task difficulty in normal individuals is increased activation of areas involved in an easier version of the task and/or the recruitment of additional brain areas (Grady et al., 1996; Grasby et al., 1994; Gur et al., 1988; Rypma et al., 1999). Therefore, areas reportedly associated with compensatory activation that have been identified in experiments

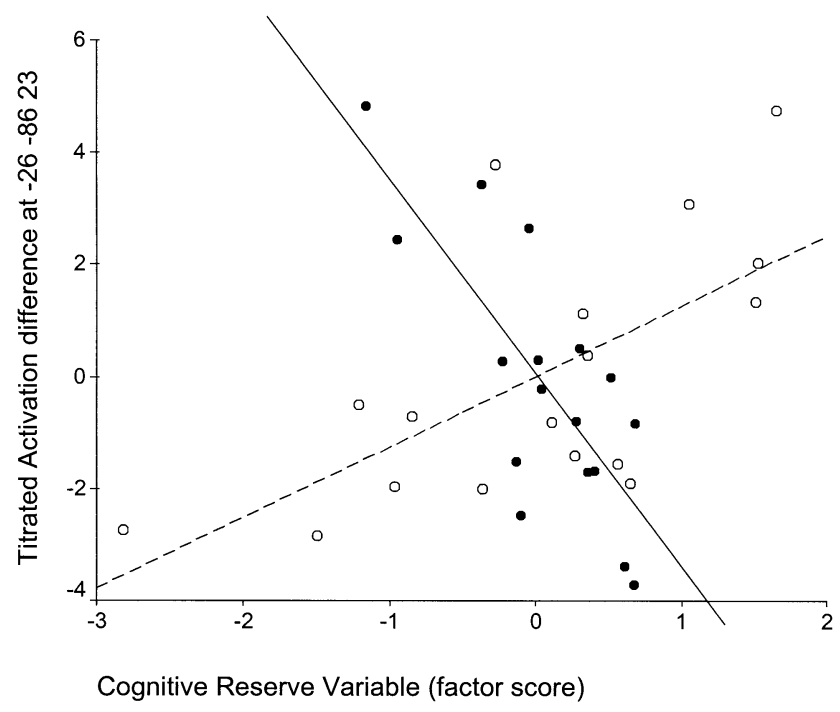

Fig. 7. Voxel-wise multiple regression of cognitive reserve variable ( $x$ axis) against TA ( $y$ axis) for the two age groups in voxel $x=-26, y=-86, z$ $=23$ (left cuneus; Brodmann's area 19). Young in black circles-solid regression line, old in white circles-dashed regression line. 


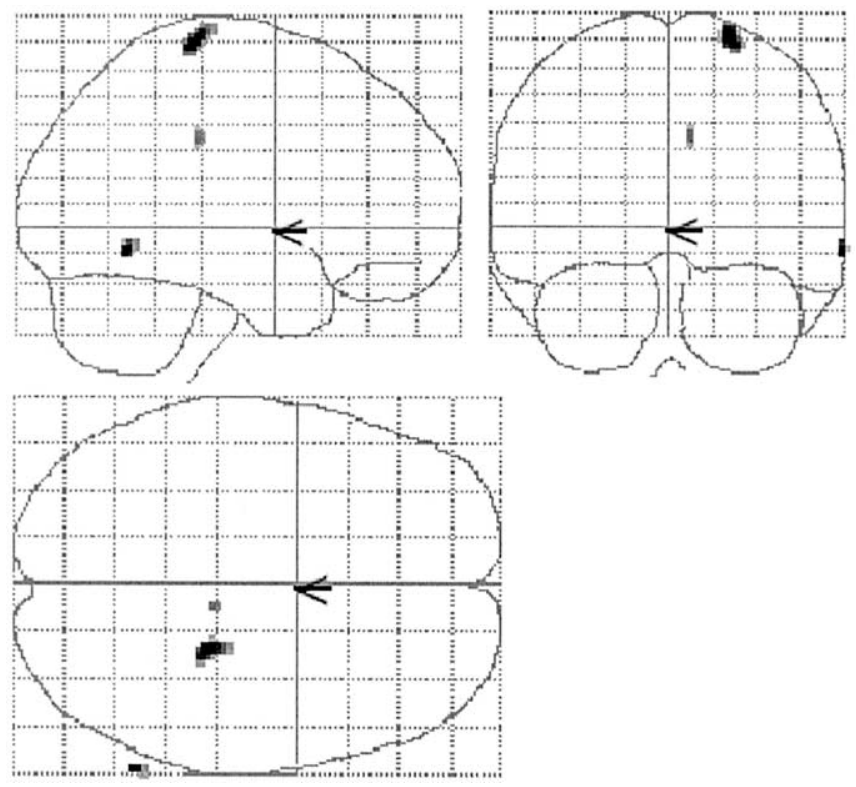

Fig. 8. Two-dimensional projections (glass brain) of statistical parametric map depicting areas where regression slopes of CRV against brain activation differences (TD-NMC) were significantly more positive in the young than the elderly $(P<0.05$ Bonferroni corrected).

with uncontrolled task difficulty may reflect modulation of the same network in response to age-differential difficulty rather than compensatory recruitment.

Some functional imaging studies have been carefully designed to ensure that observed group differences are not simply a function of task difficulty. These efforts have involved either using high-functioning subjects who behaviorally perform as well as the control group (Cabeza et al., 1997, 2002) or by tailoring each subject's task demands to a fixed performance (Stern et al., 2000). We adopted the latter approach by titrating shape list size during the experiment such that recognition accuracy was about $75 \%$ for each individual subject. Although the titration was successful (average percentage correct was $78 \%$ for the young and $72 \%$ for the elderly), there were residual deviations from this target value (range of accuracy was $59-89 \%$ for the young and $61-84 \%$ for the elderly). Moreover, there was a modest positive correlation between $\mathrm{CRV}$ and subject accuracy in the TD condition $(r=0.42, P<0.05)$. Therefore, we additionally controlled for these residual accuracy differences by including it as a predictor in the regression analyses. This was intended to ensure that any observed associations between CRV and brain activation were not (to a first approximation) attributable to residual differences in task difficulty across subjects.

It could be argued that an inherent weakness of an experimental design that controls for task difficulty is that it inevitably results in different subjects engaging different levels or intensities of cognitive processing. This argument, though intuitively compelling, is self-contradicting in its most primitive interpretation. If difficulty is the critical variable to equate between subjects, then this implies that the value of superficial task parameters (e.g., the size of the shape list or stimuli presentation time) per se is not. This study did not address which variable is most important. Therefore, we feel our results should be interpreted only in the context of matched difficulty.

\section{Slopes of CRV on rCBF vs mean rCBF effects}

Most brain imaging studies have used mean activation differences in order to identify areas that participate in various cognitive tasks. Different mean activation patterns between young and old have been shown in multiple episodic memory PET or fMRI experiments (for review see Cabeza, 2001). In the current study, there was no overlap between brain areas that evinced mean TD minus NMC activation and areas where correlations with $\mathrm{CRV}$ were observed [data not shown here, but are the main focus of another paper (Anderson et al., in preparation)]. It is plausible that all the above brain areas (both areas where mean differences are noted and areas evincing correlations) participate in the task but they may do so in a functionally different way. Areas where mean differences are detected may tend to be activated by subjects in a somewhat uniform, generic way irrespective of a subject's individual characteristics. Areas with significant slopes are differentially activated as a function of $\mathrm{CR}$, and so might not tend to be detected as mean changes. The analyses conducted in the
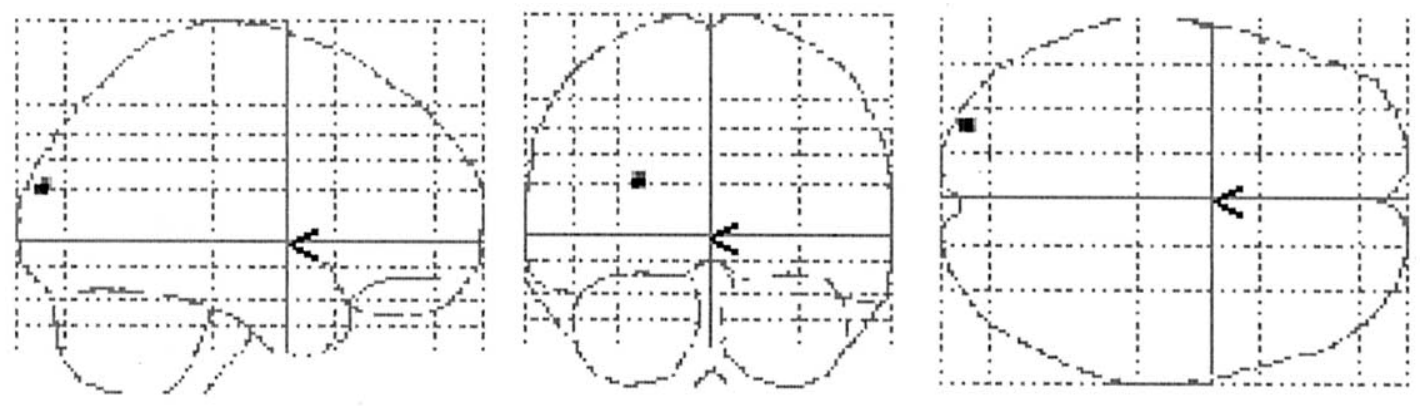

Fig. 9. Two-dimensional projections (glass brain) of statistical parametric map depicting areas where regression slopes of CRV against brain activation differences (TD-NMC) were significantly more positive in the elderly than the young $(P<0.05$ Bonferroni corrected). 
present study provide a first approximation of how ageassociated changes might be related to factors that are associated with cognitive reserve. It is plausible to hypothesize that areas where slope differences were noted may be part of the neural implementation of CR.

In both the young and the old groups, we noted areas where there was a systematic relationship between CR and brain activation. These correlations support a basic tenet of the CR hypothesis; that is, individual subjects process tasks differently as a function of CR. This may help explain individual differences in capacity in young or old individuals, and may underlie reserve against age-related changes in the elderly.

We identified areas where systematic relationships between cognitive reserve and brain activation differed as a function of aging. We observed three patterns of slope differences: (1) regions with positive slopes for the elderly and much more positive slopes for the young (e.g., Fig. 5); (2) regions with negative slopes for the elderly and positive slopes for the young (e.g., Figs. 4 and 6); and (3) regions with positive slopes for the elderly and negative slopes for the young (e.g., Fig. 7). In order to formulate hypotheses to explain the different observed patterns of slope differences, we assumed the following premises: (1) healthy subjects' activation represents optimal normal brain function while aging can cause deviations from this standard due to agerelated physiological changes; (2) higher reserve is associated with more efficient or optimal patterns of brain activation.

Given these assumptions, pattern 1 might represent an early effect of age-related changes, where high-reserve young subjects are more capable of activating specific brain areas than old subjects with high reserve. In this case, activation of this brain area is the most adaptive or efficient response to the challenge of the TD condition. The effect of aging in this case has been to reduce the ability to activate this area, while the optimal utilization of the area (i.e., increased activation) remains comparable. The reserve-related network remains comparable in the two groups, but aging may have affected the ability to invoke it.

Although activation of postcentral gyrus is not a common observation in studies of human memory, it has been reported to participate in face-name encoding tasks (Herholz et al., 2001). It was also reported to participate in a delayed match to sample face working memory task (Grady et al., 1998b), but equivalent changes in activity with increasing delay were noted for young and elderly subjects. On the contrary, word pair encoding activation in postcentral gyrus has been reported to be significantly stronger in young compared to elderly subjects (Cabeza et al., 1997). There are recent monkey studies suggesting that some somatosensory cells appear to retain visual information, suggesting that nontactile-visual stimuli have access to somatosensory cortical networks through visuohaptic associations established by behavioral training (Zhou and Fuster, 2000). In addition, vision has been recently shown to modulate somatosensory cortex activity as measured by somatosensory event-related potentials in humans (Taylor-Clarke et al., 2002). It is conceivable (although speculative) that CR is associated with visual-tactile multimodal processing and that the observed slope difference in the postcentral gyrus represents age-related decline in such visuohaptic association networks.

In a brain area where pattern 1 is noted we could hypothesize that the lower the brain activation, the more the deviation from optimal. The slope difference in this area is mostly a result of the significant positive correlation for the young (see within-group comparisons; see Table 2). The directionality of the association did not change with aging (a positive correlation between CRV and brain activation still existed also for the old). For each additional unit of CRV both the young and the old activate more; however, the elderly less so compared to the young. Old subjects with higher cognitive reserve are still able to activate this area more compared to age-matched peers with lower cognitive reserve; however, the activation per unit of CRV in the elderly is not as pronounced as in the young. We could therefore hypothesize that the higher-reserve old subjects will be more able to tolerate a subsequent disruption due to aging or $\mathrm{AD}$ pathologic insult.

Pattern 2 is noted at the right lateral temporal and cingulate gyri. Right lateral temporal activations are associated with object, facial, and spatial/motion perception, object working memory, and visual episodic memory encoding (Cabeza and Nyberg, 2000). It was the significant positive association between CRV and brain activation in the young group in contrast to a nonsignificant negative correlation for the older group (Table 2) that produced the significant slope difference in the right lateral temporal region (Fig. 5). Right lateral temporal parietal activation in the young but not in the old, during episodic retrieval and in particular during temporal order retrieval, has been noted in previous studies (Cabeza et al., 1997, 2000). We can therefore hypothesize that in this right temporal location, with aging, a loss of a positive association (increased activation with increasing cognitive reserve) seems to take place; this is replaced by a weak deactivation with increasing cognitive reserve.

The cingulate gyrus seems to play a role in episodic memory retrieval (Cabeza and Nyberg, 2000). High-resolution EEG mapping studies have associated cingulate cortex involvements with increasing task difficulty (memory load) in working memory tasks (Gevins et al., 1997). Along the same lines, fMRI studies have reported cingulate activations with increasing volitional amount of effort during visual choice reaction tasks (Winterer et al., 2002). Age-related differences in mean cingulate activations have been noted in previous studies (Cabeza et al., 1997). Decreased cingulate activation in the elderly has been shown for both episodic memory encoding and retrieval processes (Madden et al., 1999). Young subjects have also been shown to activate posterior cingulate regions during episodic memory retrieval under full attention (Anderson et al., 2000). During 
face memory tasks, young but not old subjects have been shown to invoke posterior cingulate regions (Grady et al., 1998a). The slope differences in this area are mostly a result of the significant negative correlation for the elderly (while a nonsignificant positive correlation existed for the young in the within-group comparisons; see Table 2). Aging seems to result in an significant deactivation of the posterior cingulate for increasing cognitive reserve, which replaces a weak positive association for young (increased activation for increasing CRV).

The opposite pattern (pattern 3) was noted in left cuneus: the higher the CRV the more elderly subjects were engaging these areas (and the more the young were disengaging). Although many studies support an age-associated reduction in mean occipital activations in the elderly, there are reports of increased mean left occipital Brodman area 19 activations in the elderly compared to the young during location matching perceptual tasks (Grady et al., 1994), delayed facial memory matching tasks (Grady et al., 1998a), and episodic memory encoding and retrieval tasks (Anderson et al., 2000).

In contrast to pattern 1, patterns 2 and 3 could represent situations where the increasing levels of reserve are associated with opposite direction of activation in the young and old groups. For example, in pattern 2, young subjects show increased activation of a brain area as a function of CR while there is a negative relation with $\mathrm{CR}$ in the old subjects. Given the assumptions stated above, the old, high-CR subjects are showing the optimal response in the face of aging. However, this optimal response differs from that noted in the young subjects. This suggests that this brain area is a locus for compensatory reorganization of brain function in the face of age-related changes. In order for the aged brain to perform optimally, it must utilize some brain areas in a different manner. This meets the formal definition for compensation that we have suggested (Stern, 2002): an alteration in brain function results in a change in network expression that is intended to maintain optimal function.

The approach taken here of comparing slopes across the old and young subjects differs markedly from previous studies in the literature that investigated group differences in mean activation. To our knowledge, correlations between brain activation and CRV have not been reported in the literature. One should therefore keep in mind the limitations of our attempt to functionally interpret brain areas identified with the current approach: it is based on information from studies that evaluated mean activation differences as opposed to our current approach. Further, the TD condition (after cognitive subtraction of the NMC condition) is likely to make demands on networks mediating working memory processes, episodic memory encoding, storage, and retrieval. Given the nature of PET data, it was not possible to separate the effects of different cognitive processes taking place during the task. This hinders comparison with other studies of encoding or retrieval in aging.

The current analyses point to brain areas where there may be reorganization of brain responses as a response to aging. As a test of the concept of CR, the results demonstrate that there are differences in this reorganization as a function of the $\mathrm{CR}$ variable. This is a first step toward understanding the neural implementation of reserve and compensation.

\section{Acknowledgments}

This work was supported by federal Grants AG 14671 and RR 00645.

\section{References}

Alexander, G.E., Furey, M.L., Grady, C.L., Pietrini, P., Brady, D.R., Mentis, M.J., Schapiro, M.B., 1997. Association of premorbid intellectual function with cerebral metabolism in Alzheimer's disease: implications for the cognitive reserve hypothesis. Am. J. Psychiatry. 154 (2), $165-172$.

Anderson, K.E., Scarmeas, N., Lynch, K., Zarahn, E., Luber, B., Van Heertum, R., Sackeim, H., Moeller, J.R., Stern, Y. Impairment of nonverbal recognition with normal aging: a PET O-15 study, in preparation.

Anderson, N.D., Iidaka, T., Cabeza, R., Kapur, S., McIntosh, A.R., Craik, F.I., 2000. The effects of divided attention on encoding- and retrievalrelated brain activity: a PET study of younger and older adults. J. Cogn. Neurosci. 12 (5), 775-792.

Andrade, A., Paradis, A.L., Rouquette, S., Poline, J.B., 1999. Ambiguous results in functional neuroimaging data analysis due to covariate correlation. NeuroImage 10 (4), 483-486.

Arbuckle, T.Y., Gold, D.P., Andres, D., Schwartzman, A., Chaikelson, J., 1992. The role of psychosocial context, age, and intelligence in memory performance of older men. Psychol. Aging 7 (1), 25-36.

Backman, L., Andersson, J.L., Nyberg, L., Winblad, B., Nordberg, A., Almkvist, O., 1999. Brain regions associated with episodic retrieval in normal aging and Alzheimer's disease. Neurology 52 (9), 1861-1870.

Buschke, H., Fuld, P.A., 1974. Evaluating storage, retention, and retrieval in disordered memory and learning. Neurology 24 (11), 1019-1025.

Butler, S.M., Ashford, J.W., Snowdon, D.A., 1996. Age, education, and changes in the Mini-Mental State Exam scores of older women: findings from the Nun Study. J. Am. Geriatr. Soc. 44 (6), 675-681.

Cabeza, R., 2001. Functional neuroimaging of cognitive aging, in: Cabeza, R., Kingstone, A. (Eds.), Handbook of Functional Neuroimaging of Cognition, MIT Press, Cambridge, MA, pp. 331-377.

Cabeza, R., Anderson, N.D., Houle, S., Mangels, J.A., Nyberg, L., 2000. Age-related differences in neural activity during item and temporalorder memory retrieval: a positron emission tomography study. J. Cogn. Neurosci. 12 (1), 197-206.

Cabeza, R., Anderson, N.D., Locantore, J.K., McIntosh, A.R., 2002. Aging gracefully: compensatory brain activity in high-performing older adults. NeuroImage 17 (3), 1394-1402.

Cabeza, R., Grady, C.L., Nyberg, L., McIntosh, A.R., Tulving, E., Kapur, S., Jennings, J.M., Houle, S., Craik, F.I., 1997. Age-related differences in neural activity during memory encoding and retrieval: a positron emission tomography study. J. Neurosci. 17 (1), 391-400.

Cabeza, R., Nyberg, L., 2000. Imaging cognition. II. An empirical review of 275 PET and fMRI studies. J. Cogn. Neurosci. 12 (1), 1-47.

Canadian Study of Health and Aging Working Group, 1994. Canadian study of health and aging: study methods and prevalence of dementia. Can. Med. Assoc. J. 150 (6), 899-913.

Craik, F.I.M., Byrd, M., 1982. Aging and cognitive deficits: the role of attentional resources, in: Craig, F.I.M., Trehub, S. (Eds.), Aging and Cognitive Processes, Plenum, New York, NY, pp. 191-211. 
de Leon, M.J., George, A.E., Ferris, S.H., Christman, D.R., Fowler, J.S., Gentes, C.I., Brodie, J., Reisberg, B., Wolf, A.P., 1984. Positron emission tomography and computed tomography assessments of the aging human brain. J. Comput. Assist. Tomogr. 8 (1), 88-94.

de Leon, M.J., George, A.E., Tomanelli, J., Christman, D., Kluger, A., Miller, J., Ferris, S.H., Fowler, J., Brodie, J.D., van Gelder, P., et al., 1987. Positron emission tomography studies of normal aging: a replication of PET III and 18-FDG using PET VI and 11-CDG. Neurobiol. Aging 8 (4), 319-323.

DeCarli, C., Atack, J.R., Ball, M.J., Kay, J.A., Grady, C.L., Fewster, P., Pettigrew, K.D., Rapoport, S.I., Schapiro, M.B., 1992. Post-mortem regional neurofibrillary tangle densities but not senile plaque densities are related to regional cerebral metabolic rates for glucose during life in Alzheimer's disease patients. Neurodegeneration 1, 113-121.

Esiri, M., 1994. Dementia and normal aging: neuropathology, in: Huppert, F.A., Brayne, C., O'Connor, D.W. (Eds.), Dementia and Normal Aging, Cambridge University Press, Cambridge, UK.

Ewing, J.R., Brown, G.C., Gdowski, J.W., Simkins, R., Levine, S.R., Welch, K.M., 1989. Stroke risk and age do not predict behavioral activation of brain blood flow. Ann. Neurol. 25 (6), 571-576.

Folstein, M.F., Folstein, S.E., McHugh, P.R., 1975. "Mini-mental state.” A practical method for grading the cognitive state of patients for the clinician. J. Psychiatr. Res. 12 (3), 189-198.

Friedland, R.P., Brun, A., Budinger, T.F., 1985. Pathological and positron emission tomographic correlations in Alzheimer's disease. Lancet 1 (8422), 228.

Friston, K.J., Holmes, A.P., Worsley, K.J., Poline, J.P., C.D., F., Frackowiak, R.S.J., 1995. Statistical parametric maps in functional imaging: a general linear approach. Hum. Brain Mapping 2, 189-210.

Gevins, A., Smith, M.E., McEvoy, L., Yu, D., 1997. High-resolution EEG mapping of cortical activation related to working memory: effects of task difficulty, type of processing, and practice. Cereb. Cortex 7 (4), 374-385.

Gold, D.P., Andres, D., Etezadi, J., Arbuckle, T., Schwartzman, A., Chaikelson, J., 1995. Structural equation model of intellectual change and continuity and predictors of intelligence in older men [published erratum appears in Psychol. Aging 1998 13(3), 434]. Psychol Aging 10 (2), 294-303.

Grady, C.L., Horwitz, B., Pietrini, P., Mentis, M.J., Ungerleiter, L., Rapoport, S.I., Haxby, J., 1996. The effect of task difficulty on cerebral blood flow during perceptual matching of faces. Hum. Brain Mapping 4 (4), 227-239.

Grady, C.L., Maisog, J.M., Horwitz, B., Ungerleider, L.G., Mentis, M.J., Salerno, J.A., Pietrini, P., Wagner, E., Haxby, J.V., 1994. Age-related changes in cortical blood flow activation during visual processing of faces and location. J. Neurosci. 14 (3 Pt 2), 1450-1462.

Grady, C.L., McIntosh, A.R., Bookstein, F., Horwitz, B., Rapoport, S.I., Haxby, J.V., 1998a. Age-related changes in regional cerebral blood flow during working memory for faces. NeuroImage 8 (4), 409-425.

Grady, C.L., McIntosh, A.R., Bookstein, F., Horwitz, B., Rapoport, S.I., Haxby, J.V., 1998b. Age-related changes in regional cerebral blood flow during working memory for faces. NeuroImage 8 (4), 409-425.

Grady, C.L., McIntosh, A.R., Horwitz, B., Maisog, J.M., Ungerleider, L.G., Mentis, M.J., Pietrini, P., Schapiro, M.B., Haxby, J.V., 1995. Age-related reductions in human recognition memory due to impaired encoding. Science 269 (5221), 218-221.

Grasby, P.M., Frith, C.D., Friston, K.J., Simpson, J., Fletcher, P.C., Frackowiak, R.S., Dolan, R.J., 1994. A graded task approach to the functional mapping of brain areas implicated in auditory-verbal memory. Brain 117 (Pt. 6), 1271-1282.

Grober, E., Sliwinski, M., 1991. Development and validation of a model for estimating premorbid verbal intelligence in the elderly. J. Clin. Exp. Neuropsychol. 13 (6), 933-949.

Gur, R.C., Gur, R.E., Obrist, W.D., Skolnick, B.E., Reivich, M., 1987. Age and regional cerebral blood flow at rest and during cognitive activity. Arch. Gen. Psychiatr. 44 (7), 617-621.
Gur, R.C., Gur, R.E., Skolnick, B.E., Resnick, S.M., Silver, F.L., Chawluk, J., Muenz, L., Obrist, W.D., Reivich, M., 1988. Effects of task difficulty on regional cerebral blood flow: relationships with anxiety and performance. Psychophysiology 25 (4), 392-399.

Herholz, K., Ehlen, P., Kessler, J., Strotmann, T., Kalbe, E., Markowitsch, H.J., 2001. Learning face-name associations and the effect of age and performance: a PET activation study. Neuropsychologia 39 (6), 643650.

Hoffman, J.M., Welsh-Bohmer, K.A., Hanson, M., Crain, B., Hulette, C., Earl, N., Coleman, R.E., 2000. FDG PET imaging in patients with pathologically verified dementia. J. Nucl. Med. 41 (11), 1920-1928.

Ince, P., 2001. Pathological correlates of late-onset dementia in a multicenter community-based population in England and Wales. Lancet 357 (9251), 169-175.

Katzman, R., 1993. Education and the prevalence of dementia and Alzheimer's disease. Neurology 43 (1), 13-20.

Katzman, R., Aronson, M., Fuld, P., Kawas, C., Brown, T., Morgenstern, H., Frishman, W., Gidez, L., Eder, H., Ooi, W.L., 1989. Development of dementing illnesses in an 80-year-old volunteer cohort. Ann. Neurol. 25 (4), 317-324.

Kemper, T., 1994. Neuroanatomical and neuropathological changes in normal aging and in dementia, in: Albert, M.L., Knoepfel, J.E. (Eds.), Clinical Neurology of Aging, Oxford University Press, New York, NY, pp. $9-52$.

Kempermann, G., Kuhn, H.G., Gage, F.H., 1997a. Genetic influence on neurogenesis in the dentate gyrus of adult mice. Proc. Natl. Acad. Sci. USA 94 (19), 10409-10414.

Kempermann, G., Kuhn, H.G., Gage, F.H., 1997b. More hippocampal neurons in adult mice living in an enriched environment. Nature 386 (6624), 493-495.

Lancaster, J.L., Woldorff, M.G., Parsons, L.M., Liotti, M., Freitas, C.S., Rainey, L., Kochunov, P.V., Nickerson, D., Mikiten, S.A., Fox, P.T., 2000. Automated Talairach atlas labels for functional brain mapping. Hum. Brain Mapping 10 (3), 120-131.

Loessner, A., Alavi, A., Lewandrowski, K.U., Mozley, D., Souder, E., Gur, R.E., 1995. Regional cerebral function determined by FDG-PET in healthy volunteers: normal patterns and changes with age. J. Nucl. Med. 36 (7), 1141-1149.

Logan, J.M., Sanders, A.L., et al., 2002. Under-recruitment and nonselective recruitment: dissociable neural mechanisms associated with aging. Neuron 33 (5), 827-840.

Madden, D.J., Hoffman, J.M., 1997. Application of positron emission tomography to age-related cognitive changes, in: Krishman, K.R.R., Doraiswamy, P.M. (Eds.), Brain Imaging in Clinical Psychiatry, Dekker, New York, NY.

Madden, D.J., Turkington, T.G., Provenzale, J.M., Denny, L.L., Hawk, T.C., Gottlob, L.R., Coleman, R.E., 1999. Adult age differences in the functional neuroanatomy of verbal recognition memory. Hum. Brain Mapping 7 (2), 115-135.

Martin, W.R., Ye, F.Q., Allen, P.S., 1998. Increasing striatal iron content associated with normal aging. Mov. Disord. 13 (2), 281-286.

Mayeux, R., Stern, Y., Rosen, J., Leventhal, J., 1981. Depression, intellectual impairment, and Parkinson disease. Neurology 31 (6), 645-650.

McGeer, E.G., McGeer, P.L., Harrop, R., Akiyama, H., Kamo, H., 1990a. Correlations of regional postmortem enzyme activities with premortem local glucose metabolic rates in Alzheimer's disease. J. Neurosci. Res. 27 (4), 612-619.

McGeer, E.G., Peppard, R.P., McGeer, P.L., Tuokko, H., Crockett, D., Parks, R., Akiyama, H., Calne, D.B., Beattie, B.L., Harrop, R., 1990b. 18Fluorodeoxyglucose positron emission tomography studies in presumed Alzheimer cases, including 13 serial scans. Can. J. Neurol. Sci. 17 (1), 1-11.

McGeer, P.L., Kamo, H., Harrop, R., Li, D.K., Tuokko, H., McGeer, E.G., Adam, M.J., Ammann, W., Beattie, B.L., Calne, D.B., et al., 1986a. Positron emission tomography in patients with clinically diagnosed Alzheimer's disease. Can. Med. Assoc. J. 134 (6), 597-607. 
McGeer, P.L., Kamo, H., Harrop, R., McGeer, E.G., Martin, W.R., Pate, B.D., Li, D.K., 1986b. Comparison of PET, MRI, and CT with pathology in a proven case of Alzheimer's disease. Neurology 36 (12) 1569-1574.

McIntosh, A.R., 1999. Mapping cognition to the brain through neural interactions. Memory 7 (5-6), 523-548.

Meyer, J.S., Terayama, Y., Takashima, S., 1993. Cerebral circulation in the elderly. Cerebrovasc. Brain Metab. Rev. 5 (2), 122-146.

Mielke, R., Schroder, R., Fink, G.R., Kessler, J., Herholz, K., Heiss, W.D. 1996. Regional cerebral glucose metabolism and postmortem pathology in Alzheimer's disease. Acta Neuropathol. 91 (2), 174-179.

Nelson, H.E., 1982. The National Adult Reading Test (NART): Test Manual. NFER-Nelson, Windsor, Berkshire, UK.

Nelson, H.E., O'Connell, A., 1978. Dementia: the estimation of premorbid intelligence levels using the New Adult Reading Test. Cortex 14 (2), $234-244$.

Nguyen, H.T., Black, S.A., Ray, L.A., Espino, D.V., Markides, K.S., 2002. Predictors of decline in MMSE scores among older Mexican Americans. J. Gerontol. A Biol. Sci. Med. Sci. 57 (3), M181-M185.

Raz, N., Gunning, F.M., Head, D., Dupuis, J.H., McQuain, J., Briggs, S.D. Loken, W.J., Thornton, A.E., Acker, J.D., 1997. Selective aging of the human cerebral cortex observed in vivo: differential vulnerability of the prefrontal gray matter. Cereb. Cortex 7 (3), 268-282.

Reuter-Lorenz, P., 2002. New visions of the aging mind and brain. Trends Cogn. Sci. 6 (9), 394.

Reuter-Lorenz, P.A., Jonides, J., Smith, E.E., Hartley, A., Miller, A., Marshuetz, C., Koeppe, R.A., 2000. Age differences in the frontal lateralization of verbal and spatial working memory revealed by PET. J. Cogn. Neurosci. 12 (1), 174-187.

Rypma, B., D’Esposito, M., 2001. Age-related changes in brain-behaviour relationships: evidence from event-related functional MRI studies. European J. Cogn. Psychol. 13, 235-256.

Rypma, B., Prabhakaran, V., Desmond, J.E., Glover, G.H., Gabrieli, J.D., 1999. Load-dependent roles of frontal brain regions in the maintenance of working memory. NeuroImage 9 (2), 216-226.

Scarmeas, N., Levy, G., Tang, M., Manly, J., Stern, Y., 2001. Influence of leisure activity on the incidence of Alzheimer's disease. Neurology 57 (12), 2236-2242.

Scarmeas, N., Zarahn, E., Anderson, K.E., Habeck, C., Hilton, J., Flynn, J., Marder, K., Bell, K., Sackeim, H., Van Heertum, R., Moeller, J.R., Stern, Y., 2003. Association of life activities with cerebral blood flow in Alzheimer's disease: implications for the cognitive reserve hypothesis. Arch. Neurol., 60 (3), 359-365.

Schochet Jr., S.S., 1998. Neuropathology of aging. Neurol. Clin. 16 (3) $569-580$

Snowdon, D.A., Greiner, L.H., Markesbery, W.R., 2000. Linguistic ability in early life and the neuropathology of Alzheimer's disease and cerebrovascular disease. Findings from the Nun Study. Ann. NY Acad. Sci. 903, 34-38.
Snowdon, D.A., Ostwald, S.K., Kane, R.L., 1989a. Education, survival, and independence in elderly Catholic sisters, 1936-1988. Am. J. Epidemiol. 130 (5), 999-1012.

Snowdon, D.A., Ostwald, S.K., Kane, R.L., Keenan, N.L., 1989b. Years of life with good and poor mental and physical function in the elderly. J. Clin. Epidemiol. 42 (11), 1055-1066.

Stern, Y., 2002. What is cognitive reserve? Theory and research application of the reserve concept. J. Int. Neuropsychol. Soc. 8 (3), 448-460.

Stern, Y., Alexander, G.E., Prohovnik, I., Mayeux, R., 1992. Inverse relationship between education and parietotemporal perfusion deficit in Alzheimer's disease. Ann. Neurol. 32 (3), 371-375.

Stern, Y., Alexander, G.E., Prohovnik, I., Stricks, L., Link, B., Lennon, M.C., Mayeux, R., 1995. Relationship between lifetime occupation and parietal flow: implications for a reserve against Alzheimer's disease pathology. Neurology 45 (1), 55-60.

Stern, Y., Gurland, B., Tatemichi, T.K., Tang, M.X., Wilder, D., Mayeux, R., 1994. Influence of education and occupation on the incidence of Alzheimer's disease. J. Am. Med. Assoc. 271 (13), 1004-1010.

Stern, Y., Moeller, J.R., Anderson, K.E., Luber, B., Zubin, N.R., DiMauro, A.A., Park, A., Campbell, C.E., Marder, K., Bell, K., Van Heertum, R., Sackeim, H.A., 2000. Different brain networks mediate task performance in normal aging and AD: defining compensation. Neurology 55 (9), 1291-1297.

Stern, Y., Sano, M., Paulson, J., Mayeux, R., 1987. Modified mini-mental state examination: validity and reliability. Neurology 37 (Suppl. 1), 179.

Strong, R., 1998. Neurochemical changes in the aging human brain: implications for behavioral impairment and neurodegenerative disease. Geriatrics 53 (Suppl. 1), S9-S12.

Talairach, J., Tournoux, P., 1988. Co-Planar Stereotaxic Atlas of the Human Brain. Thieme Medical Publishers, Stutgart.

Taylor-Clarke, M., Kennett, S., Haggard, P., 2002. Vision modulates somatosensory cortical processing. Curr. Biol. 12 (3), 233-236.

van Praag, H., Kempermann, G., Gage, F.H., 1999. Running increases cell proliferation and neurogenesis in the adult mouse dentate gyrus. Nature Neurosci. 2 (3), 266-270.

Wechsler, D., 1981. Wechler Adult Intelligence Scale Revised. The Psychological Corp., New York.

Wilson, R.S., Mendes de Leon, C.F., Barnes, L., Schneider, J.A., Bienias, J.L., Evans, D.A., Bennett, D.A., 2002. Participation in cognitively stimulating activities and risk of incident Alzheimer disease. J. Am. Med. Assoc. 287 (6), 742-748.

Winterer, G., Adams, C., Jones, D., Knutson, B., 2002. Volition to action-an event-related fMRI study. NeuroImage 17 (2), 851.

Zarahn, E., 2002. Using larger dimensional signal-subspaces to increase sensitivity in fMRI time series analyses. Hum. Brain Mapping 17 (1), 13-16.

Zhou, Y.D., Fuster, J.M., 2000. Visuo-tactile cross-modal associations in cortical somatosensory cells. Proc. Natl. Acad. Sci. USA 97 (17), 9777-9782. 